Retraction

\title{
Retracted: Superoxide-Dismutase Deficient Mutants in Common Beans (Phaseolus vulgaris L.): Genetic Control, Differential Expressions of Isozymes, and Sensitivity to Arsenic
}

\author{
BioMed Research International \\ Received 7 August 2016; Accepted 7 August 2016 \\ Copyright (c) 2016 BioMed Research International. This is an open access article distributed under the Creative Commons \\ Attribution License, which permits unrestricted use, distribution, and reproduction in any medium, provided the original work is \\ properly cited.
}

BioMed Research International has retracted the article titled "Superoxide-Dismutase Deficient Mutants in Common Beans (Phaseolus vulgaris L.): Genetic Control, Differential Expressions of Isozymes, and Sensitivity to Arsenic" [1]. The article was found to contain images with signs of duplication and manipulation in Figures 1, 3, 4, 5(A), 5(B), 6, 8(b), 9(C), 9(G), $9(\mathrm{I})$, and $9(\mathrm{~J})$.

\section{References}

[1] D. Talukdar and T. Talukdar, "Superoxide-dismutase deficient mutants in common beans (Phaseolus vulgaris L.): genetic control, differential expressions of isozymes, and sensitivity to arsenic," BioMed Research International, vol. 2013, Article ID 782450, 11 pages, 2013. 